\title{
EFFECTS OF NANO MINERAL-SUPPLEMENTED DIET ON PIG GROWTH
}

\author{
Hoang Nghia Son \\ Institute of Tropical Biology, VAST, Vietnam \\ Received 25 December 2019, accepted 10 March 2020
}

\begin{abstract}
This paper examined the effects of nano mineral supplementation of diets on the growth of pigs. The total of 180 pigs used for this study were classified into 4 experimental groups and one control group. The results showed that the weight of pigs at the beginning and the end of the experiment was insignificantly different between experimantal and control groups. The same daily gain weight was observed between experimental and control groups. However, the feed conversion ratio (FCR) of four experimental groups I, II, III and IV is $3.00 \pm 0.28,2.95 \pm 0.11$, $2.85 \pm 0.19$ and $2.90 \pm 0.24$, respectively, that were lower than of the control groups, i.e. $3.17 \pm$ 0.42. The mineral content of $\mathrm{Fe}, \mathrm{Cu}, \mathrm{Zn}$ and $\mathrm{Mn}$ in liver of pigs in all the experimental groups is lower than that in liver of pigs in the control group. In addition, the amount of Fe and $\mathrm{Zn}$ metal in urine and feces of the experimental groups is also lower than in the control group. The results of our study showed that the addition of nano minerals in diets for pigs not only reduced the feed conversion ratio in pigs, also decreased the amount of minerals releasing into the environment.
\end{abstract}

Keywords: Feed conversion ratio, nano minerals, residual metals, weight gain.

Citation: Hoang Nghia Son, 2020. Effects of nano mineral-supplemented diet on pig growth. Tap chi Sinh hoc, 42(1): 125-131. https://doi.org/10.15625/0866-7160/v42n1.14863.

*Corresponding author email: hoangnghiason@yahoo.com

(C2020 Vietnam Academy of Science and Technology (VAST) 


\title{
ẢNH HƯởNG CỦA BỔ SUNG KHOÁNG NANO TRONG KHẨU PHẦ THỨC ĂN ĐẾN KHẢ NĂNG SINH TRƯởNG CỦA LỢN TH!̣T
}

\author{
Hoàng Nghĩa Sơn \\ Viện Sinh học nhiệt đới, Viện Hàn lâm Khoa học và Công nghệ Việt Nam \\ Ngày nhận bài 25-12-2019, ngày chấp nhận 10-3-2020
}

\section{TÓM TÁ́T}

Nghiên cứu này được thực hiện nhằm đánh giá ảnh hưởng của việc bổ sung nano khoáng trong khẩu phần thức ăn đến sự tăng trưởng của lợn thịt. Tổng số 180 lợn thịt sử dụng cho nghiên cứu này, được chia thành 4 nhóm thí nghiệm và nhóm đối chứng, mỗi nhóm 3 ô, mỗi ô 12 con (tương ứng 3 lần lặp lại). Kết quả nghiên cứu cho thấy, khối lượng lợn thịt lúc bắt đầu và kết thúc thí nghiệm không có sự khác biệt về mặt thống kê. Khối lượng tăng trọng/ngày của lợn thịt giữa nhóm đối chứng và nhóm thí nghiệm như nhau. Tuy nhiên, chỉ số chuyển hóa thức ăn của 4 nhóm thí nghiệm I, II, III và IV tương ứng $3,00 \pm 0,28 ; 2,95 \pm 0,11 ; 2,85 \pm 0,19$ và $2,90 \pm 0,24$ đều thấp hơn so với nhóm đối chứng $(3,17 \pm 0,42)$. Hàm lượng kim loại $\mathrm{Fe}, \mathrm{Cu}, \mathrm{Zn}$ và $\mathrm{Mn}$ tồn dư trong gan lợn thịt đều thấp hơn so với ở nhóm đối chứng. Ngoài ra, lượng kim loại Fe và $\mathrm{Zn}$ trong nước tiểu và phân của các nhóm thí nghiệm cũng thấp hơn so với nhóm đối chứng. Các kết quả trên cho thấy việc bổ sung nano khoáng trong thức ăn đã giúp tăng khả năng chuyển hóa thức ăn ở lợn thịt, giảm lượng thức ăn cho $1 \mathrm{~kg}$ tăng trọng đồng thời làm giảm lượng các kim loại thải ra môi trường.

Từ khóa: Khoáng nano, tăng trọng, tồn dư kim loại, tỉ lệ chuyển hóa thức ăn (FCR).

*Địa chỉ liên hệ email: hoangnghiason@yahoo.com

\section{MỞ ĐẦU}

Khoáng chất, đặc biệt là vi khoáng, đóng vai trò rất quan trọng trong sự sinh trưởng và phát triển của lợn. Một số khoáng chất như canxi $(\mathrm{Ca})$, clorua $(\mathrm{Cl})$, đồng $(\mathrm{Cu})$, iốt $(\mathrm{I})$, sắt $(\mathrm{Fe})$, mangan $(\mathrm{Mn})$, phốt pho $(\mathrm{P})$, selen $(\mathrm{Se})$, natri $(\mathrm{Na})$ và kẽm $(\mathrm{Zn})$ dưới dạng phụ gia thức ăn được bổ sung thường xuyên vào chế độ ăn của lợn (Morris, 1987). Khoáng chất hỗ trợ từ chức năng cấu trúc trong xương đến nhiều phản ứng hóa học cần thiết cho việc duy trì, tăng trưởng, sinh sản và lợn cho con bú (Conrad et al., 1980). Đồng, sắt và kẽm được bổ sung vào thức ăn cho lợn như chất kích thích tăng trưởng, khoáng chất thiết yếu, chất điện giải và giảm tiêu chảy ở lợn non, hỗ trợ tiêu hóa cho thời kỳ mang thai và cho con bú ở lợn nái (Dréau \& Lallés, 1999; Burton,
2007). $\mathrm{Cu}$ và $\mathrm{Zn}$ đóng vai trò quan trọng trong các quá trình sinh lý ở lợn, giúp đáp ứng yêu cầu tăng trưởng bình thường của lợn (Jacela et al., 2010). Nghiên cứu của Hill \& Spears (2001) cho thây, khi $\mathrm{Cu}$ và $\mathrm{Zn}$ được bổ sung ở hàm lượng cao trên mức yêu cầu của động vật (100-250 ppm Cu và 2.000-3.000 ppm Zn) có thể làm tăng hiệu suất tăng trưởng của lợn. Sắt cũng là một thành phần quan trọng khác cho sự tăng trưởng ở lợn, tình trạng thiếu máu thường liên quan đến lợn bị thiếu sắt trong chế độ ăn uống hoặc từ môi trường của chúng (Anderson \& Easter, 1999). Hiện nay, việc bổ sung nano khoáng đã trở nên phô biến vì nhiều lợi ích nó mang lại, như tăng khả năng hấp thu, giảm hàm lượng bổ sung khoáng, và đặc biệt là giảm lượng khoáng thải ra môi trường. Trong nghiên cứu này chúng tôi đánh giá ảnh hưởng của việc bổ sung nano khoáng 
trong khẩu phần thức ăn lên sự tăng trưởng của lợn thịt cũng như đánh giá hiệu quả chuyển hóa thức ăn, đặc biệt là xác định mức độ các kim loại đã được bồ sung còn tồn dư trong phân và nước tiểu của lợn.

\section{VÂT LIỆU VÀ PHƯƠNG PHÁP NGHIÊN CứU}

\section{Chuẩn bị thức ăn}

Các loại khoáng nano gồm $\mathrm{nFe}, \mathrm{nCu}, \mathrm{nZn}$, $\mathrm{nMn}, \mathrm{nSe}$ và $\mathrm{nCo}$ được cung cấp bởi Viện Công nghệ môi trường, Viện Hàn lâm Khoa học và Công nghệ Việt nam. Trong đó $n F e$, $\mathrm{nCu}, \mathrm{nZn}, \mathrm{nMn}$ và nCo ở dạng bột; nSe ở dạng dung dịch.

Hỗn hợp bột $\mathrm{nFe}, \mathrm{nCu}, \mathrm{nZn}, \mathrm{nMn}$ và $\mathrm{nCo}$ được cân và xử lý bằng siêu âm trong máy siêu âm G08 (Đức) trong 30 phút. Sau đó, dung dịch nSe được phối trộn với các khoáng trên. Lượng thức ăn phù hợp sẽ được trộn với hỗn hợp trên với tốc độ 200 vòng/phút (thường thì lượng thức ăn và khoáng tương ứng được tính để cho lợn ăn trong 1 tuần, nếu nhiều quá thức ăn dễ bị mốc, nếu ít quá sẽ tốn nhiều công phối trộn). Thức ăn sau khi trộn nano khoáng được chuẩn bị trong túi 25 $\mathrm{kg}$, cho ăn hàng ngày. Lượng thức ăn cho ăn tự do và thức ăn thừa được thu gom, cân vào cuối ngày.

\section{Thiết kế thí nghiệm}

Thí nghiệm được thực hiện tại trang trại Chu Quang Dũng, xã Nhị Bình, huyện Hóc Môn, Thành phố Hồ Chí Minh. Tổng cộng có 180 lợn thịt 2 máu (Landrac + Duroc) được sử dụng trong nghiên cứu này. Khối lượng trung bình của lợn lúc bắt đầu thí nghiệm khoảng $20-22 \mathrm{~kg}$.

Lợn được đánh số và phân thành 4 nhóm thí nghiệm và nhóm đối chứng $(\mathrm{ÐC})$, các nhóm có tỷ lệ đực, cái bằng nhau, mỗi nhóm chia 3 ô, mỗi ô 12 con (tương ứng 3 lần lặp lại). Lợn thịt thuộc nhóm đối chứng được cho ăn bổ sung khoáng chất vô cơ theo khuyến nghị của NRC 1998 đối với lợn thịt. Lợn thịt thuộc 4 nhóm I, II, II và IV được cho ăn bằng chế độ ăn cơ bản bổ sung khoáng nano. Hàm lượng bổ sung khoáng nano vào thức ăn nhóm $\mathrm{I}(\mathrm{mg} / \mathrm{kg}$ thức ăn): $\mathrm{nMn}=0,8 \mathrm{mg} / \mathrm{kg} ; \mathrm{nFe}=20$ $\mathrm{mg} / \mathrm{kg} ; \mathrm{nCu}=2 \mathrm{mg} / \mathrm{kg} ; \mathrm{nCo}=0,1 \mathrm{mg} / \mathrm{kg}$; $\mathrm{nSe}=0,1 \mathrm{mg} / \mathrm{kg}$; và $\mathrm{nZn}=20 \mathrm{mg} / \mathrm{kg}$. Hàm lượng khoáng nano được sử dụng cho nhóm II, III và IV lần lượt cao hơn 2,4 và 8 lần so với nhóm I.

\section{Đo nồng độ kim loại}

Mẫu gan, phân và nước tiểu của lợn được gửi đến công ty xét nghiệm phân tích Việt Tín (79 Trương Định, phường Bến Thành, Quận 1, Thành phố Hồ Chí Minh) để xác định nồng độ kim loại.

\section{Đo khối lượng lợn}

Lợn được giữ trong lồng riêng biệt và cân bằng cân điện tử chuyên dụng. Chỉ số cân nặng được xác định đối với lợn khi bắt đầu thí nghiệm và lợn xuất chuồng. Các số liệu cân nặng được thu nhận theo từng cá thể lợn được sử dụng trong thí nghiệm này lúc bắt đầu thí nghiệm và lúc kết thúc thí nghiệm.

\section{Thu thập dữ liệu và phân tích thống kê}

Ảnh hưởng của chế độ ăn bổ sung khoáng nano đến năng suất lợn thịt được đánh giá qua khối lượng lợn thịt tại thời điểm bắt đầu và kết thúc thí nghiệm, tỉ lệ tăng trọng, hiệu quả chuyển hóa thức ăn (FCR), dư lượng các khoáng kim loại trong gan, phân và nước tiểu của lợn thịt. Phân tích thống kê được thực hiện bằng one way $\mathrm{ANOVA}$, giá trị $\mathrm{P} \leq 0,05$ được đánh giá là có ý nghĩa thống kê.

\section{KẾT QUẢ}

\section{Ảnh hưởng của nano khoáng lên sự tăng trọng}

Khối lượng của các cá thể lợn bắt đầu thí nghiệm được mô tả trong bảng 1 . Khối lượng bắt đầu thí nghiệm giữa các nhóm thí nghiệm tương đương nhau và không có sự khác biệt thống kê. Khối lượng lợn lúc kết thúc thí nghiệm (xuất chuồng) ở nhóm đối chứng, nhóm I, II, III và IV tương ứng là 105,82 ; 104,$33 ; 105,83 ; 107,43$ và $106,57 \mathrm{~kg} / \mathrm{con}$ (bảng 1). Các giá trị này không có sự khác biệt về mặt thống kê. Các nhóm thí nghiệm và nhóm đối chứng cũng cho thấy sự tương đương trong giá trị tăng trọng trung bình/ngày. 
Giá trị FCR (hệ số chuyển hóa thức ăn) của nhóm đối chứng là $3,17 \pm 0,42$, giá trị này cao hơn so với các nhóm thí nghiệm khác $(\mathrm{P}<$ 0,05). Giá trị FCR của 4 nhóm I, II, III, IV tương ứng: $3,00 \pm 0,28 ; 2,95 \pm 0,11 ; 2,85 \pm$ 0,$19 ; 2,90 \pm 0,24$ (hình 1 ). Giá trị FCR giữa các nhóm thử nghiệm với nano khoáng không có sự khác biệt về mặt thống kê.

Bảng 1. Ảnh hưởng của nano khoáng lên sự tăng trọng của lợn

\begin{tabular}{|l|c|c|c|c|c|}
\hline \multicolumn{1}{|c|}{ Chỉ tiêu theo dõi } & ĐC & Nhóm I & Nhóm II & Nhóm III & Nhóm IV \\
\hline $\begin{array}{l}\text { Khối lượng bắt đầu } \\
\text { thí nghiệm }(\mathrm{kg})\end{array}$ & $21,80 \pm 0,50$ & $21,67 \pm 0,67$ & $21,73 \pm 0,43$ & $21,93 \pm 0,41$ & $21,80 \pm 0,60$ \\
\hline $\begin{array}{l}\text { Khối lượng xuất } \\
\text { chuồng (kg) }\end{array}$ & $105,82 \pm 3,43$ & $104,33 \pm 2,57$ & $105,83 \pm 1,04$ & $107,43 \pm 1,92$ & $106,57 \pm 2,11$ \\
\hline $\begin{array}{l}\text { Tăng trọng trung } \\
\text { bình/ngày }(\mathrm{kg})\end{array}$ & $0,99 \pm 0,04$ & $0,97 \pm 0,03$ & $0,99 \pm 0,01$ & $1,01 \pm 0,02$ & $1,00 \pm 0,02$ \\
\hline
\end{tabular}

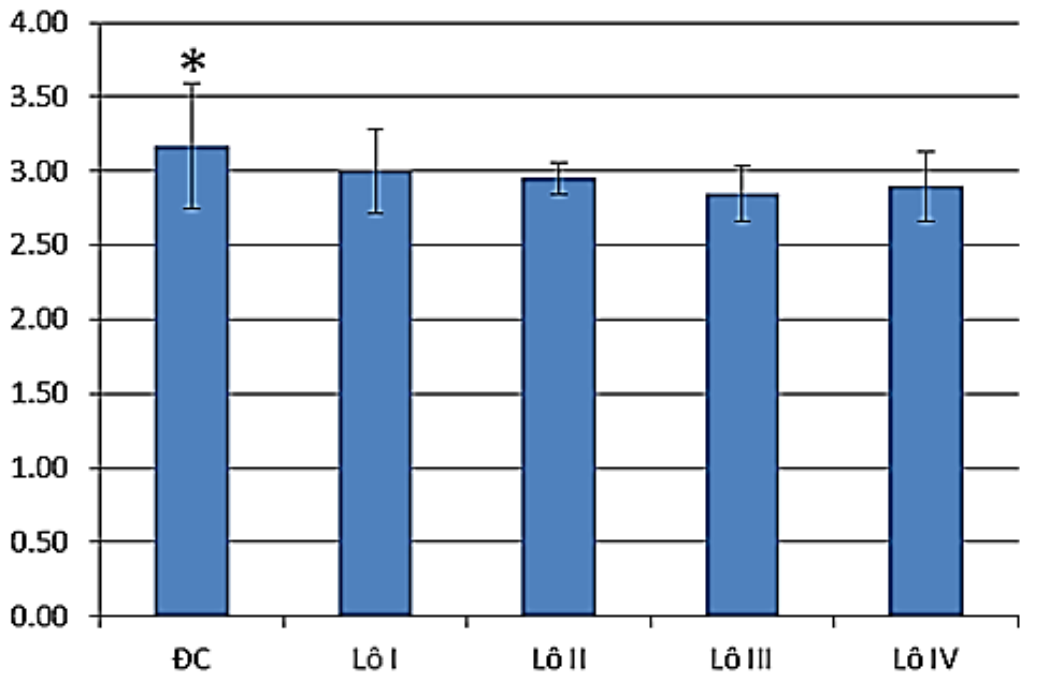

Hình 1. Hệ số chuyển hóa thức ăn trên lợn thịt ở các nhóm thí nghiệm,

(*) $\mathrm{P}<0,05$ (Nhóm đối chứng với các nhóm khác)

\section{Dư lượng khoáng trong gan lọn thịt}

Hàm lượng $\mathrm{Fe}$ có trong gan lợn thịt ở nhóm $\mathrm{ĐC}$ và nhóm IV là cao nhất và không có sự sai khác giữa 2 nhóm này $(178,13 \pm 16,10$ $\mathrm{mg} / \mathrm{kg}$ và $145,33 \pm 2,03 \mathrm{mg} / \mathrm{kg}$ ). Hàm lượng Fe có trong gan lợn thịt ở ba nhóm I, II và III tương ứng là $83,20 \pm 18,64 \mathrm{mg} / \mathrm{kg} ; 78,67 \pm$ $11,53 \mathrm{mg} / \mathrm{kg}$ và $129,00 \pm 8,33 \mathrm{mg} / \mathrm{kg}$, thấp hơn có ý nghĩa thống kê so với nhóm IV và nhóm đối chứng với $\mathrm{P}<0,05$. Tuy nhiên, không có sự khác biệt về mặt thống kê trong hàm lượng sắt giữa các nhóm I, II và III.

Hàm lượng $\mathrm{Cu}$ có trong gan lợn thịt ở nhóm ĐC cao nhất $(24,57 \pm 3,12 \mathrm{mg} / \mathrm{kg})$, cao hơn nhóm I $(13,40 \pm 1,00 \mathrm{mg} / \mathrm{kg})(\mathrm{P}<0,001)$.
Hàm lượng $\mathrm{Cu}$ trong gan lợn con ở ba nhóm II, III và IV tương ứng: $19,43 \pm 1,83 ; 16,87 \pm$ 0,67 và $19,50 \pm 0,61 \mathrm{mg} / \mathrm{kg}$, tuy nhiên, các kết quả này không có sự khác biệt về mặt thống kê.

Hàm lượng $\mathrm{Zn}$ trong gan ở lợn thịt ở nhóm đối chứng cũng cao nhất (137,73 \pm $12,61 \mathrm{mg} / \mathrm{kg}$ ), cao hơn có ý nghĩa thống kê với $\mathrm{P}<0,001$ so với bốn nhóm $\mathrm{I}, \mathrm{II}$, III và IV $(85,00 \pm 6,30 ; 86,70 \pm 0,01 ; 92,90 \pm 3,10$; $102,67 \pm 1,45 \mathrm{mg} / \mathrm{kg}$ ). Hàm lượng Mn trong gan ở lợn thịt nhóm ĐC cao nhất $(4,44 \pm 0,39$ $\mathrm{mg} / \mathrm{kg}$ ), cao hơn có ý nghĩa thống kê so với cả bốn nhóm I, II, III và IV $(2,41 \pm 0,17$; $2,64 \pm 0,12 ; 2,71 \pm 0,09 ; 3,02 \pm 0,11 \mathrm{mg} / \mathrm{kg}$ ) $(\mathrm{P}<0,001)$. 
Effects of nano mineral - supplemented diet

Bảng 2. Hàm lượng khoáng tồn dư trong trong gan lợn thịt

\begin{tabular}{|l|c|c|c|c|c|}
\hline $\begin{array}{c}\text { Chỉ tiêu theo } \\
\text { dõi }\end{array}$ & Nhóm ĐC & Nhóm I & Nhóm II & Nhóm III & Nhóm IV \\
\hline $\begin{array}{l}\text { Hàm lượng } \\
\text { Fe (mg/kg) }\end{array}$ & $\begin{array}{c}178,13 \pm 16,10 \\
(\mathrm{P}<0,01 \text { vs. I,II })\end{array}$ & $83,20 \pm 18,64$ & $78,67 \pm 11,53$ & $129,00 \pm 8,33$ & $\begin{array}{c}145,33 \pm 2,03 \\
(\mathrm{P}<0,01 \mathrm{vs.} \mathrm{I,II)}\end{array}$ \\
\hline $\begin{array}{l}\text { Hàm lượng } \\
\mathrm{Cu}(\mathrm{mg} / \mathrm{kg})\end{array}$ & $\begin{array}{c}24,57 \pm 3,12 \\
(\mathrm{P}<0,001 \text { vs. I) }\end{array}$ & $13,40 \pm 1,00$ & $19,43 \pm 1,83$ & $16,87 \pm 0,67$ & $19,50 \pm 0,61$ \\
\hline $\begin{array}{l}\text { Hàm lượng } \\
\text { Zn (mg/kg) }\end{array}$ & $\begin{array}{c}137,73 \pm 12,61 \\
(\mathrm{P}<0,001 \text { vs. I,II, III, IV) }\end{array}$ & $85,00 \pm 6,30$ & $86,70 \pm 0,01$ & $92,90 \pm 3,10$ & $102,67 \pm 1,45$ \\
\hline $\begin{array}{l}\text { Hàm lượng } \\
\mathrm{Mn}(\mathrm{mg} / \mathrm{kg})\end{array}$ & $\begin{array}{c}4,44 \pm 0,39 \\
(\mathrm{P}<0,001 \text { vs. I,II, III, IV) }\end{array}$ & $2,41 \pm 0,17$ & $2,64 \pm 0,12$ & $2,71 \pm 0,09$ & $3,02 \pm 0,11$ \\
\hline
\end{tabular}

Dư lượng khoáng trong nước tiểu và phân lọnn thịt

Trong nước tiểu của lợn ở nhóm I và II không phát hiện $\mathrm{Fe}, \mathrm{Cu}, \mathrm{Zn}$ và $\mathrm{Mn}$ (bảng 3 ). Ở nhóm III chỉ phát hiện Fe với hàm lượng 0,25 $\pm 0,10 \mathrm{mg} / \mathrm{L}$, hàm lượng này ít hơn so với $\mathrm{Fe}$ ở nhóm ĐC $(0,88 \pm 0,10 \mathrm{mg} / \mathrm{L})$ và nhóm $\mathrm{IV}$ $(0,69 \pm 0,12 \mathrm{mg} / \mathrm{L})$, giữa nhóm $\mathrm{C}$ và nhóm IV không có sự sai khác thống kê. Ở nhóm $\mathrm{DC}$ và nhóm $\mathrm{IV}$ còn phát hiện hàm lượng $\mathrm{Zn}$ tương ứng 0,15 và $0,05 \mathrm{mg} / \mathrm{L}$.

Bảng 3. Hàm lượng khoáng tồn dư trong nước tiểu lợn thịt

\begin{tabular}{|l|c|c|c|c|c|}
\hline $\begin{array}{c}\text { Chỉ tiêu theo dõi } \\
(\mathrm{mg} / \mathrm{L})\end{array}$ & Nhóm ĐC & Nhóm I & Nhóm II & Nhóm III & Nhóm IV \\
\hline Hàm lượng Fe & $\begin{array}{c}0,88 \pm 0,10 \\
(\mathrm{P}<0,05 \text { vs. III })\end{array}$ & - & - & $0,25 \pm 0,10$ & $\begin{array}{c}0,69 \pm 0,12 \\
(\mathrm{P}<0,05 \text { vs. III })\end{array}$ \\
\hline Hàm lượng Cu & - & - & - & - & - \\
\hline Kẽm (Zn) & 0,15 & - & - & - & 0,05 \\
\hline Mangan $(\mathrm{Mn})$ & - & - & - & - & - \\
\hline
\end{tabular}

Ghi chú: "-”: Không phát hiện.

Ngoài ra, chúng tôi còn đánh giá hàm lượng kim loại $\mathrm{Fe}, \mathrm{Cu}, \mathrm{Zn}$ và $\mathrm{Mn}$ tồn dư trong phân ở lợn thịt của nhóm ĐC và nhóm III. Hàm lượng $\mathrm{Fe}$ và $\mathrm{Zn}$ trong phân ở nhóm $\mathrm{ĐC}$ $(526,00 \pm 10,00 \mathrm{mg} / \mathrm{L}$ và $950,50 \pm$
14,50mg/L) cao hơn có ý nghĩa thống kê so với nhóm III $(418,00 \pm 20,00 \mathrm{mg} / \mathrm{L}$ và 664,50 $\pm 114,50 \mathrm{mg} / \mathrm{L}$ ) (bảng 4 ). Hàm lượng $\mathrm{Cu}$ và Mn tồn dư trong phân tương đối thấp và không có sự sai khác giữa 2 nhóm.

Bảng 4. Hàm lượng khoáng tồn dư trong phân lợn thịt

\begin{tabular}{|l|c|c|}
\hline \multicolumn{1}{|c|}{ Chỉ tiêu theo dõi } & Nhóm ĐC & Nhóm III \\
\hline Hàm lượng $\mathrm{Fe}(\mathrm{mg} / \mathrm{L})$ & $526,00 \pm 10,00(\mathrm{P}<0,05$ vs. III $)$ & $418,00 \pm 20,00$ \\
\hline Hàm lượng $\mathrm{Cu}(\mathrm{mg} / \mathrm{kg})$ & $592,50 \pm 19,50$ & $491,00 \pm 26,00$ \\
\hline Hàm lượng $\mathrm{Zn}(\mathrm{mg} / \mathrm{kg})$ & $950,50 \pm 14,50(\mathrm{P}<0,05 \mathrm{vs}$. III) & $664,50 \pm 11,50$ \\
\hline Hàm lượng $\mathrm{Mn}(\mathrm{mg} / \mathrm{kg})$ & $436,00 \pm 15,00$ & $375,00 \pm 22,00$ \\
\hline
\end{tabular}

\section{THẢO LUẬN}

Khoáng vi lượng (vi khoáng) là các kim loại, là các nguyên tố được đặc trưng bởi mật độ và khối lượng nguyên tử tương đổi cao với số nguyên tử lớn hơn 20 (Raskin et al., 1994). Một số kim loại như coban $(\mathrm{Co})$, đồng $(\mathrm{Cu})$, sắt $(\mathrm{Fe})$, mangan $(\mathrm{Mn})$, molybdenum $(\mathrm{Mo})$, niken $(\mathrm{Ni})$ và kẽm $(\mathrm{Zn})$ là bắt buộc với hàm lượng nhỏ trong nhu cầu của sinh vật, tuy nhiên lượng kim loại này dư thừa có thể trở nên có hại cho loài sinh vật (Chibuike \& Obiora, 2014). Mặc dù thực vật và động vật cần một số kim loại nhất định cho sự tăng 
trưởng và duy trì chức năng của chúng, tuy nhiên, nếu lượng các kim loại này được bổ sung quá mức có thể trở nên độc hại đối với chúng (Djingova \& Kuleff, 2000).

Trong nghiên cứu này, chúng tôi nhận thấy không có sự khác nhau về khối lượng lợn lúc kết thúc thí nghiệm, cũng như tăng trọng trung bình/ngày, tuy nhiên, giá trị FCR ở lợn thịt của các nhóm thí nghiệm đều giảm so với nhóm đối chứng. Kết quả này cho thấy khả năng chuyển hóa thức ăn của lợn thịt ở nhóm sử dụng khoáng nano tốt hơn so với nhóm đối chứng. Điều này chứng tỏ thức ăn bổ sung khoáng nano có tác dụng giúp tăng khả năng sinh trưởng của lợn thịt, giảm lượng thức ăn cần dùng để tăng trọng $1 \mathrm{~kg}$ cho lợn. Chúng tôi nhận thấy với mức bổ sung khoáng nano như ở lô III là hợp lý nhất, vừa giúp lợn tăng trọng nhanh lại có hệ số chuyển hóa thức ăn tốt nhất. Ngoài ra, việc sử dụng nano khoáng cũng làm giảm hàm lượng kim loại tồn dư trong gan của lợn thịt.

Mặc dù vi khoáng có tác động tích cực đến chăn nuôi lợn, việc sử dụng các vi khoáng này ở mức độ cao sẽ dẫn đến ô nhiễm đất nơi phân lợn được thải ra trong thời gian dài (Wei \& Yang, 2010). Điều này là do dư thừa các kim loại trong cơ thể lợn và có thể thoát ra từ phân của chúng vào đất. Hơn $95 \%$ lượng đồng và kẽm của lợn thải ra môi trường được bài tiết qua phân (Hays, 2013). Trong nghiên cứu này, việc sử dụng nano khoáng cho thấy sự giảm rõ rệt hàm lượng kim loại thải ra môi trường, Đặc biệt lợn ở nhóm thí nghiệm III có chỉ số chuyển hóa thức ăn tốt nhất, không phát hiện các kim loại $\mathrm{Cu}, \mathrm{Zn}$ và $\mathrm{Mn}$ trong nước tiểu, trong khi đó, hàm lượng $\mathrm{Fe}$ thấp hơn nhiều so với nhóm đối chứng. Hơn nữa, lượng kim loại $\mathrm{Fe}$ và $\mathrm{Zn}$ tồn dư trong phân cũng thấp hơn so với nhóm đối chứng. Các kết quả trên cho thấy việc bổ sung các nano khoáng như $\mathrm{nFe}, \mathrm{nCu}, \mathrm{nZn}, \mathrm{nMn}$ không chỉ hiệu quả trong việc giảm chỉ số chuyển hóa thức ăn, mà còn giảm lượng kim loại tồn dư trong chất thải của lợn thịt, điều này góp phần tăng lợi ích kinh tế cũng như giảm thiểu tác động gây ô nhiễm môi trường từ chất thải chăn nuôi.

\section{TÀI LIÊUU THAM KHẢO}

Anderson B. K., Easter R. A., 1999. A review of iron nutrition in pigs. Illinois Livestock Trail, University of Illinois Extension.

Burton C. H., 2007. The potential contribution of separation technology to the management of livestock manure. Livestock Science, 112: 208-216.

Chibuike G. U., Obiora S. C., 2014. Heavy metal polluted soils: Effect on plants and bioremediation methods. Appl Environ Soil Sci. Article ID 752708: 1-12.

Conrad H. R., Zimmerman D. R., Combs G. F. J., 1980. NFIA, Literature review on Iron in animal and poultry nutrition. National Iron Ingredients Association, West Des Moines, IA.

Djingova R., Kuleff I., 2000. Instrumental techniques for trace analysis. In: Trace Element: Their distribution and effects in the environment, Vernet JP (ed.), Elsevier, London, UK.

Dréau D., Lallés J. P., 1999. Contribution to the study of gut hypersensitivity reaction from livestock slurry applied to grassland. Grass Fora Sci., 53: 31-40.

Hays V. W., 2013. Effectiveness of feed additive usage of antibacterial agents in swine and poultry production. Prim Source Edn Nabu Press, 108.

Hill G. M., Spears J. W., 2001. Trace and ultra-trace elements in swine nutrition. In: Swine Nutrition, Lewis AJ, Southern LL (edtrs), CRC Press. Boca Raton, Florida: 229-261.

Jacela J. Y., DeRouchey J. M., Tokach M. D., Goodband R. D., 2010. Feed additives for swine: Fact sheets-high dietary levels of copper and zinc for young pigs and phytase. J. Swine Health Prod., 18: 87-91.

Morris E. R. 1987. Trace elements in human and animal nutrition. Mertz $W$ ed. Academic Press, New York. 
Raskin I., Nanda-Kumar P. B. A., Dushenkov S., Salt D. E., 1994. Bioconcentration of heavy metals by plants. Curr Opin Biotechnol., 5: 285-290.
Wei B., Yang L., 2010. A review of heavy metal contamination in urban soils, urban road dust and agricultural soils from China. Microchem. J., 94: 99-107. 